\title{
Management of a Severe Form of Verneuil's Disease in Its Genitoperineal Localisation in Bobo-Dioulasso
}

\author{
Zare Cyprien ${ }^{1}$, Ouattara Adama ${ }^{1}$, Kambou Timothée$^{1}$, Ouangre Edgar², Diallo Boukary ${ }^{3}$, \\ Traore A. Ibrahim1, Barro Drissa1, Sanon G. Bakary1, Ye 0. Delphine1, Traore S. Simon² \\ ${ }^{1}$ Department of Surgery, University Teaching Hospital Souro Sanou, Bobo-Dioulasso, Burkina Faso \\ ${ }^{2}$ Visceral Surgery, University Teaching Hospital Yalgado Ouedraogo, Ouagadougou, Burkina Faso \\ ${ }^{3}$ Department of Medicine and Medical Specialties, University Teaching Hospital, Bobo-Dioulasso, Burkina Faso \\ Email: ${ }^{*}$ zcyprien@yahoo.fr
}

Received 22 January 2015; accepted 10 February 2015; published 11 February 2015

Copyright (C) 2015 by authors and Scientific Research Publishing Inc.

This work is licensed under the Creative Commons Attribution International License (CC BY). http://creativecommons.org/licenses/by/4.0/

(c) ()

\section{Abstract}

The authors report a severe form of genitoperineal localisation of Verneuil's disease managed in a surgical environment, having evolved favorably with improvement of the patient's quality of life, but persistence of unsightly skin scars. They insist on the unexceptional nature of this disease whose prognosis is reserved, sometimes leaving severe functional sequelae. The long evolution of the disease with prolonged hospitalization in a professionally active young patient and the extension of suppurations to the perineal, scrotal and inguinal regions was the features of this observation. After wide excision of the lesions with antibiotic associated with local care, evolution had taken to complete wound healing with improved quality of life and a recovery of his professional activity.

\section{Keywords}

Verneuil's Disease, Hydradenitis Suppurativa, Genitoperineal, Surgery

\section{Introduction}

Verneuil's disease or hydradenitis suppurativa is a chronic suppurating, fistulizing and sclerosing disease of skin areas with apocrine glands that diagnosis is mainly clinical [1] [2]. It is characterized by painful subcutaneous nodules, fistulae, abscesses, infiltrated closets and fibrous scars. It interests mostly axilla and genitoperineal re-

\footnotetext{
${ }^{*}$ Corresponding author.
}

How to cite this paper: Cyprien, Z., Adama, O., Timothée, K., Edgar, O., Boukary, D., Ibrahim, T.A., Drissa, B., Bakary, S.G., Delphine, Y.O. and Simon, T.S. (2015) Management of a Severe Form of Verneuil's Disease in Its Genitoperineal Localisation in Bobo-Dioulasso. Open Journal of Urology, 5, 13-18. http://dx.doi.org/10.4236/oju.2015.52003 
gions and may affect the patient's quality of life in severe forms [3] [4]. Hydradenitis suppurativa treatment is surgical and must be adapted to each patient depending on the extent of the disease, locations and extension [4]. Surgical removal of all suppurations remains the treatment of choice for a cure and patient's quality of life improvement [5] [6]. From this observation, we present our experience in managing this debilitating disease in its genitoperineal form highlighting the deterioration of the quality of life and the difficulty of its management.

\section{Observation}

Mr. S. Y., 30 years old, a teacher, was received in consultation July 12, 2013 for recurrent chronic suppuration of the perineal region. The onset of symptoms dated back to 2008 by the appearance of nodular abscesses in the right axilla and secondarily perineal area. These intermittent first lesions became permanent after six months and were more marked in the perineal region. Despite antibiotics, suppuration had gradually extended to scrotal and inguinal regions annoying enormously patient with impaired quality of life. The patient was forced to wear layers, he had to change it three to four times a day; thus forcing him to quit his teaching function. The examination noted that he was a chronic smoker with an average of 15 cigarettes per day for 19 years whether 14.25 PY (pack-years of cigarettes). Physical examination noted a deterioration of general condition and multiple nodular areas with purulent ooze of perineal and inguinoscrotal regions. A medical treatment with isotretinoin initiated in dermatology was marked by very bothersome side effects with little effect on the course of the disease. The paraclinical realized including MRI, HIV status, AARB research, syphilis and blood glucose was normal. Faced with this clinical picture of chronic suppuration of perineal, scrotal and inguinal regions, the diagnosis of Verneuil's disease in its advanced form, perineal inguinal scrotal localization was mentioned (Figure 1). A surgical procedure was indicated and it consisted in total resection in two operating times of suppurations. The first surgical step was preceded by a discharge colostomy and during the operation, it was discovered an anal fistula treated by the establishment of a link with a vicryl 1 (Figure 2). At the end of two months, a good evolution of the first surgical wound (Figure 3) was obtained by a directed healing through daily dressing with povidone iodine $10 \%$ ointment and every two days with fat tulle. Given this relatively good progress, the second resection was performed taking the rest of suppurative areas (Figure 4). The result of the histological examination of surgical specimens found a non specific chronic inflammation with no signs of malignity. The wound remained open and scarring still run with local care with povidone iodine, antibiotic therapy based on ceftriaxone $1 \mathrm{G}$ twice daily parenterally for 7 days, associated tetracycline $200 \mathrm{mg}$ twice daily for one month.

The periodicity of this care was first daily, then every two days and finally weekly. Four months healing was satisfactory (Figure 5 and Figure 6) and the care was continued for two months. In six months, the evolution was satisfactory with the disappearance of suppurations but with retractable and unsightly sequelae (Figure 7). The intestinal tract continuity is then restored. Mr. SY was regularly followed in the service, to total wound healing outside retractable perineal unsightly scars. To date, he noticed a marked improvement in quality of his life and resumed his professional activities.

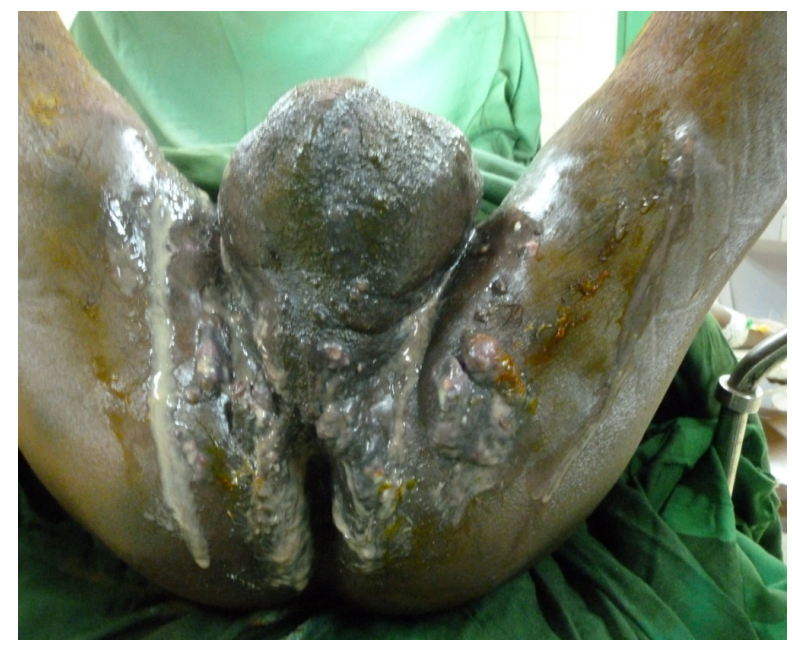

Figure 1. Genitoperineal location of Verneuil's disease. 


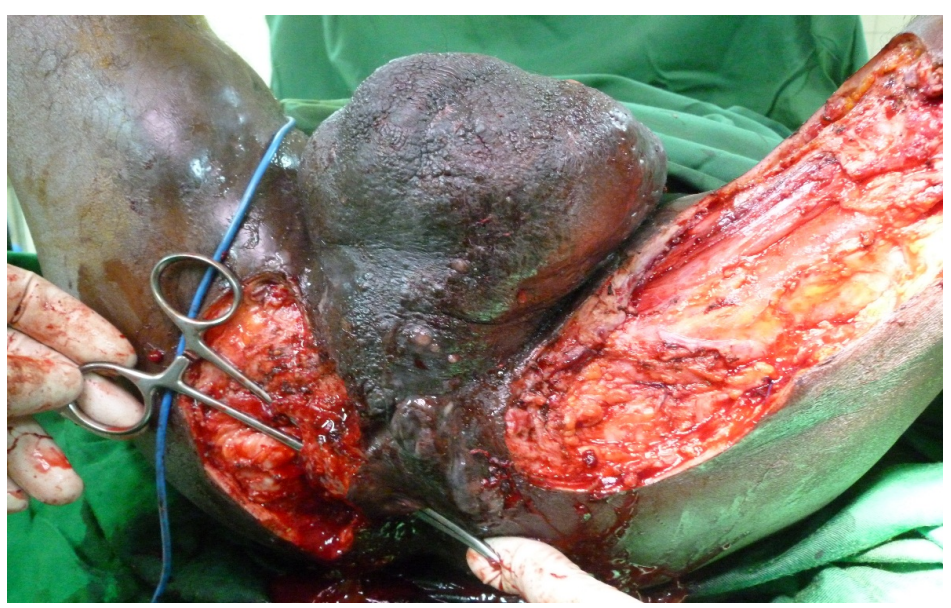

Figure 2. $\left(1^{\text {st }}\right.$ operating time of excision): Genitoperineal suppuration with anal fistula wide excision of skin and fascial covering carrying suppuration and fustula areas.

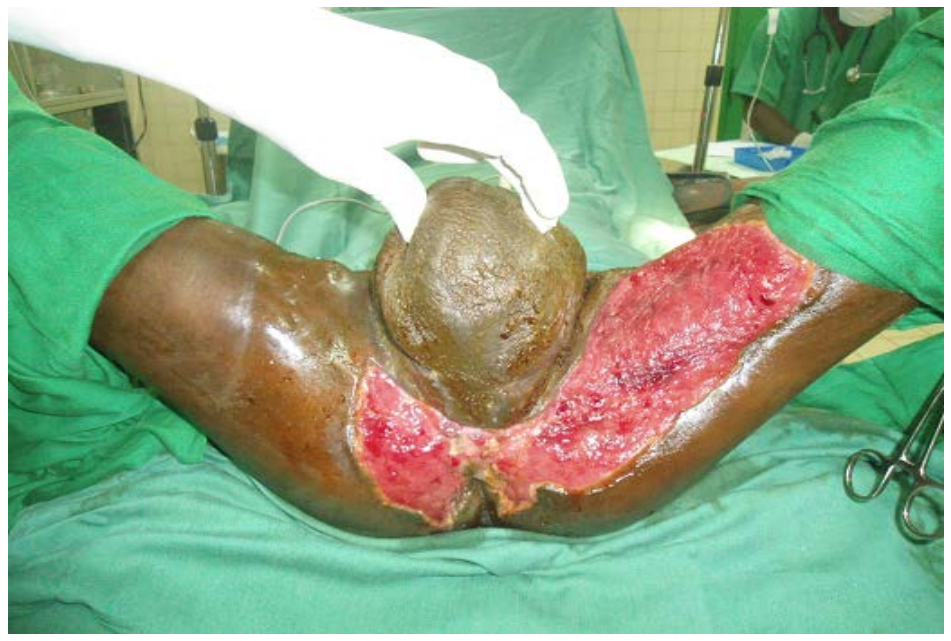

Figure 3. Lesion progression at two mouths.

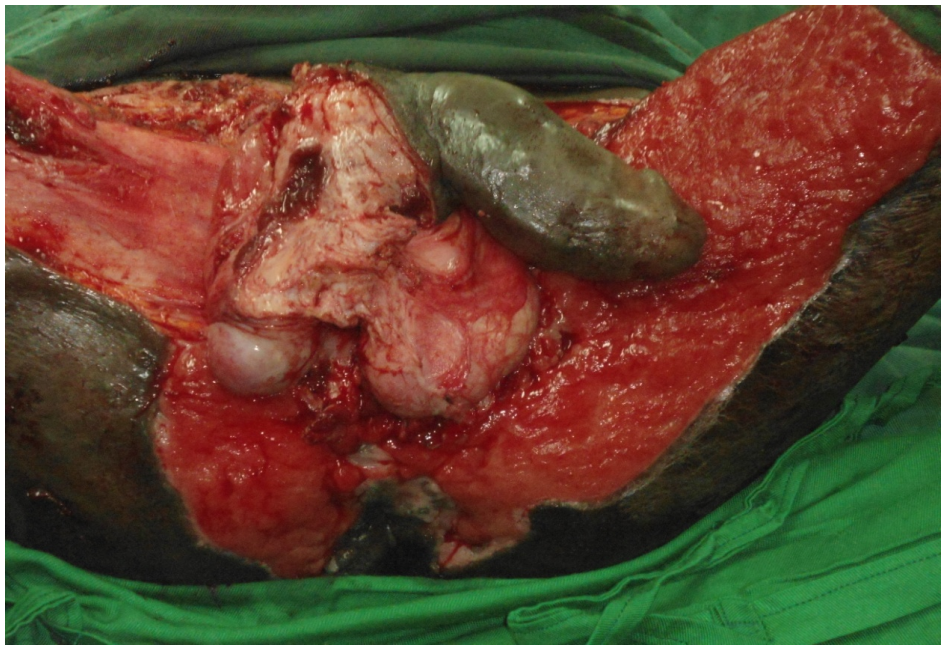

Figure 4. ( $2^{\text {nd }}$ operating time of excision): total resection from other suppurations areas. 


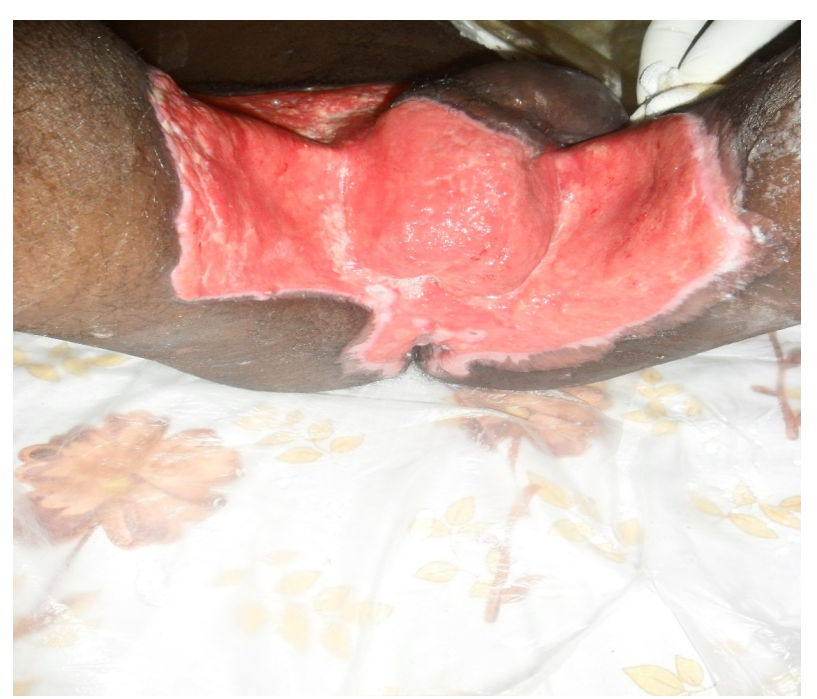

Figure 5. Lesion progression at four mouths with directed healing.

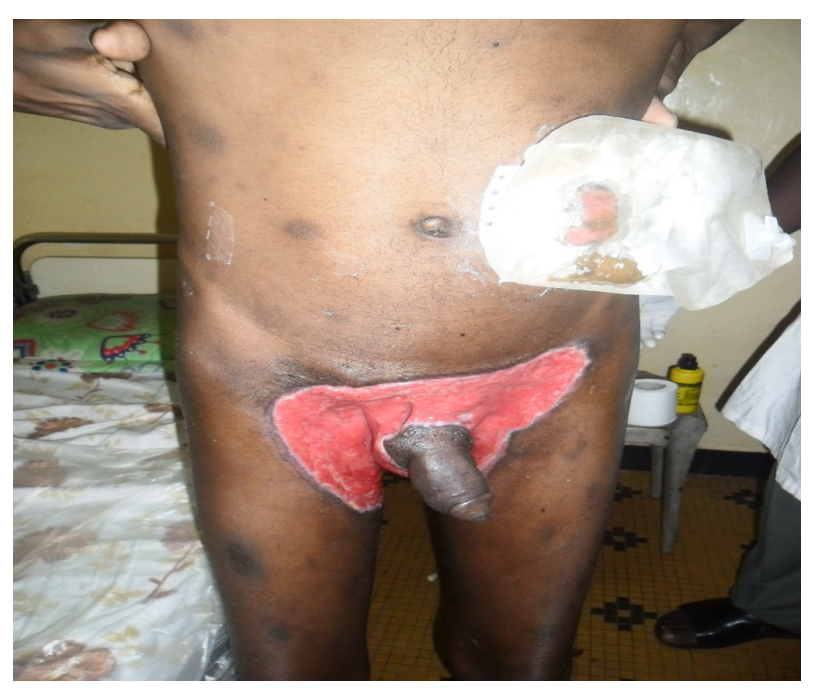

Figure 6. Progression at four mouths with transient colostomy.

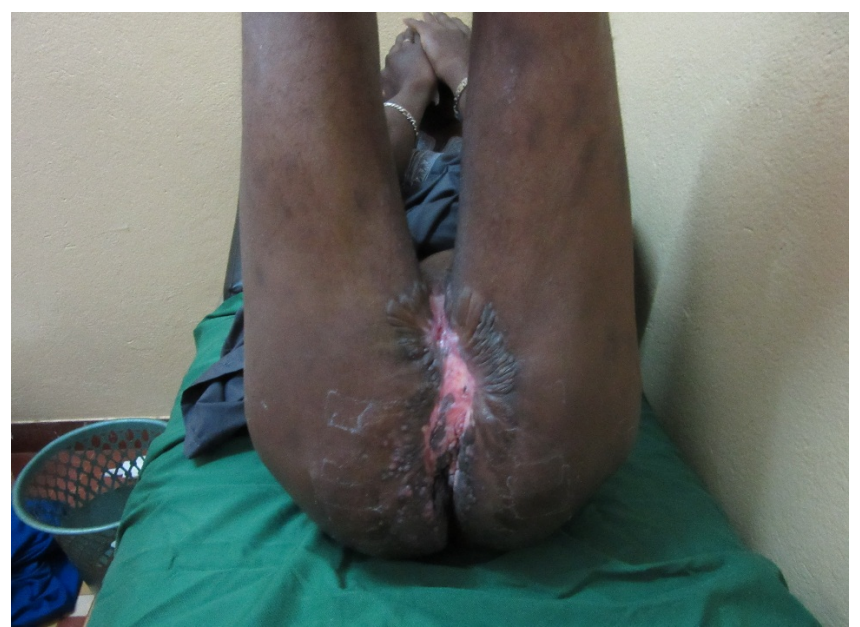

Figure 7. Final aspects of lesions with retractile and unsightly scars. 


\section{Discussion}

Verneuil's disease in its genitoperineal location is an unexceptional disease entity. The clinico-anatomical and evolving characteristics of this suppuration occurred in our patient were sufficient to make the diagnosis. Indeed according to Von der Worth, J.M., et al. cited by Sudan, D. [1], the diagnosis of Verneuil's disease is clinical. Its clinical presentation is quite unique and diagnosis does not need further investigations. It should be considered faced recurrent superficial suppuration with multiples holes, in typical topography, axillary, inguinal, perineal and/or gluteal regions and with chronic evolution. However, it should know the diagnostic traps constituted by the other suppuratives lesions and especially anal fistulae or abscesses seat. You should also remember that the risk of malignant degeneration exists, and that the association with other chronic inflammatory diseases such as Crohn's disease is not uncommon [6]. Usually it starts at the axillary region to extend later to other regions [5] as was the case in our patient.

In our case, Vermeil's disease was associated with anal fistula whose cure was made in the first operative time.

The chronicity and extension to other regions including bilateral inguinal and scrotal regions with a permanent and abundant suppuration has greatly altered the quality of life of our patients leading to the abandonment of his professional activities. Antibiotic treatment often prescribed as first-line rule is ineffective [1] [7], and does not prevent the chronicity and severity of the disease and the evidence of clinical diagnosis as during our observation.

Surgical treatment in one or more time seems to be the only radical treatment of Verneuil's disease [7] [8]. The most effective way would be a wide, total and profound surgical excision of all suppurations taking the skin and subcutaneous tissue [8] [9]. The healing of surgical wounds was obtained in this case by local health care associated with antibiotic therapy. In this observation, flap transplant recommended by Lamfichekh was not used [8]. Whereas, it was performed a discharge colostomy, given the location of the disease in the patient that the literature data do not quote as means associate to the surgical treatment. The colostomy was performed because excision was important with exposure of the testicles and the association of anal fistula treated in the first operative time. The patient is smoking, smoking cessation has been proposed, as shown by some authors [4] [7]. The evolution was satisfactory, despite a wound suppuration with retractable unsightly scars, obtained after six months of treatment (Figure 7). This support method was cumbersome and challenging for the patient, given the long duration of hospitalization; it has however allowed a total healing of lesions improved its quality of life and resumed his teaching activities. The skin graft would have to reduce our patient's hospital stay if it had been carried out. Its achievement has not been possible because of the colostomy and extent of resection extended on inner sides of the thighs. The patient was followed for a year and we did not notice any specific complications. We have particularly noted no degenerative lesion unlike Talmant, J.C., et al. who reported two cases of degenerative type squamous cell carcinoma in their series after falling a year and have identified 38 other cases in the literature [10].

\section{Conclusion}

Vermeil's disease is easily diagnosed as compared to other chronic suppurations. It has recurrent nature and usually starts at the axilla then reaches other regions including perineal, scrotal and inguinal. It is disabling in severe forms. Diagnosis and surgical treatment must be early to improve the quality of patient's life.

\section{References}

[1] Soudan, D. (2001) La maladie de Verneuil: Diagnostic-Formes Cliniques. Le courrier de colo-proctologie, 2, 17-19.

[2] Bilali, S., Todi, V., Bilali, V. and Habibaj, J. (2012) Surgical Treatment of Chronic Suppurativa in the Gluteal and Perineal Regions. Actachirluqosl, 59, 91-95.

[3] Dandy, F.W. and Margesson, I.J. (2010) Hidradenitissuppurativa. Dermatolclin, 28, 779-793.

[4] Mooij, J.E., Van't Oost, L., Leenarts, M.F. and Mekkes, J.R. (2011) Treatment Options in Severe Hidradenitis Suppurativa. Nederlands Tijdscrift Voor Geneeskunde, 155, Article ID: A1912.

[5] Buimer, M.G., Wobbes, T. and Klinkenbijl, J.H. (2009) Hidradenitissuppurativa. British Journal of Surgery, 96, 350360. http://dx.doi.org/10.1002/bjs.6569

[6] Soudan, D. (2006) Thierry du Puy-Montbrun. Maladie de Verneuil. Hépato-Gastro-Oncologie Digestive, 13, 1-9. 
[7] Pigot, F. (2001) La maladie de Verneuil. Le courrier de colo-proctologie, 2, 17-19.

[8] Lamfichekh, N., Dupond, A.S., Runser, C., Humbert, P. and Mantion, G. (2001) Traitement chirurgical de la maladie de Verneuil: 15 cas. Annale de dermatologie et vénéréologie, 128, 127.

[9] Chen, M.L., Odom, B. and Santucci, R.A. (2014) Surgical Management of Genitoperineal Hidradenitis Suppurativa in Men. Urology, 83, 1412-1417.

[10] Tamant, J.C., Bruant-Rodier, C., Nunziata, J.F. and Wilk, A. (2013) Dégénérescence de maladie de Verneuil en carcinome épidermoide: à propos de 2 cas et revue de la littérature. Annales de chirurgie plastique esthetique, 51, 82-86.

\section{Abbreviations}

AARB: Acid-Alcohol Resitant Bacillus

CHU: Sourou Sanou: University Teaching Hospital Souro Sanou

HIV: Human Immunodeficiency Virus

MRI: Magnetic Resonance Imaging

PY: Pack Year 
Scientific Research Publishing (SCIRP) is one of the largest Open Access journal publishers. It is currently publishing more than 200 open access, online, peer-reviewed journals covering a wide range of academic disciplines. SCIRP serves the worldwide academic communities and contributes to the progress and application of science with its publication.

Other selected journals from SCIRP are listed as below. Submit your manuscript to us via either submit@scirp.org or Online Submission Portal.
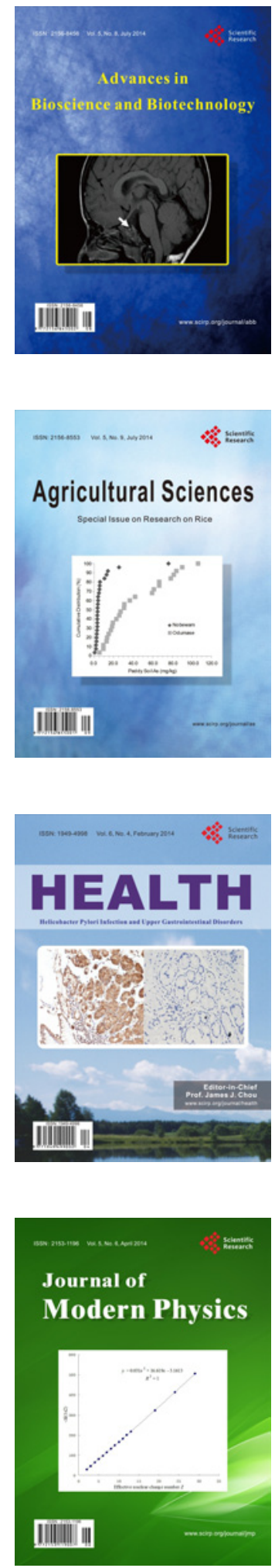
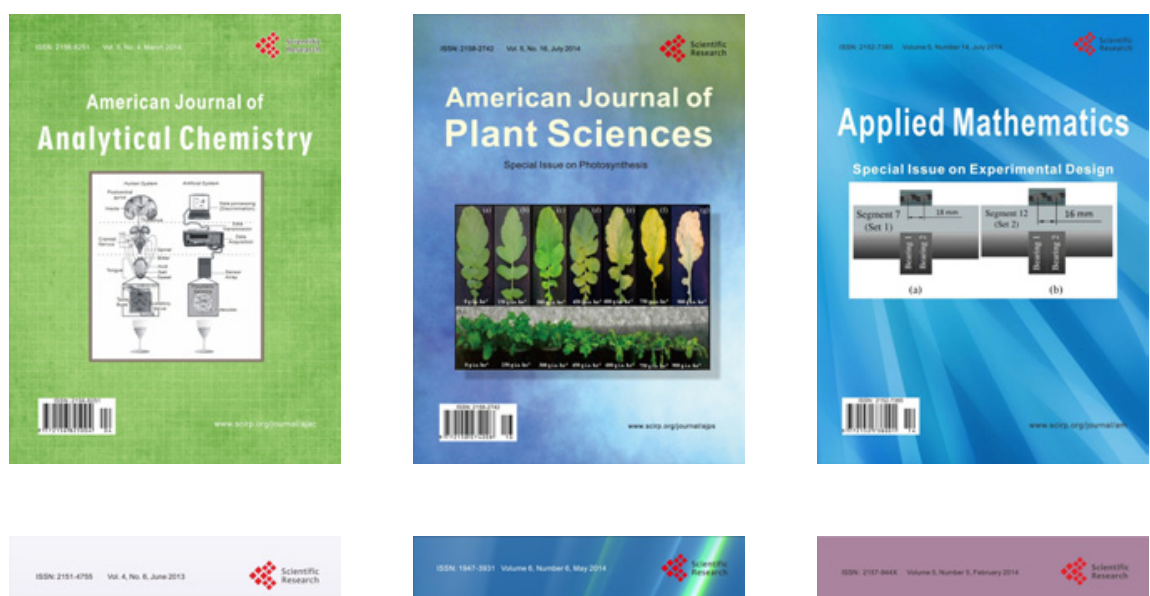

Creative Education
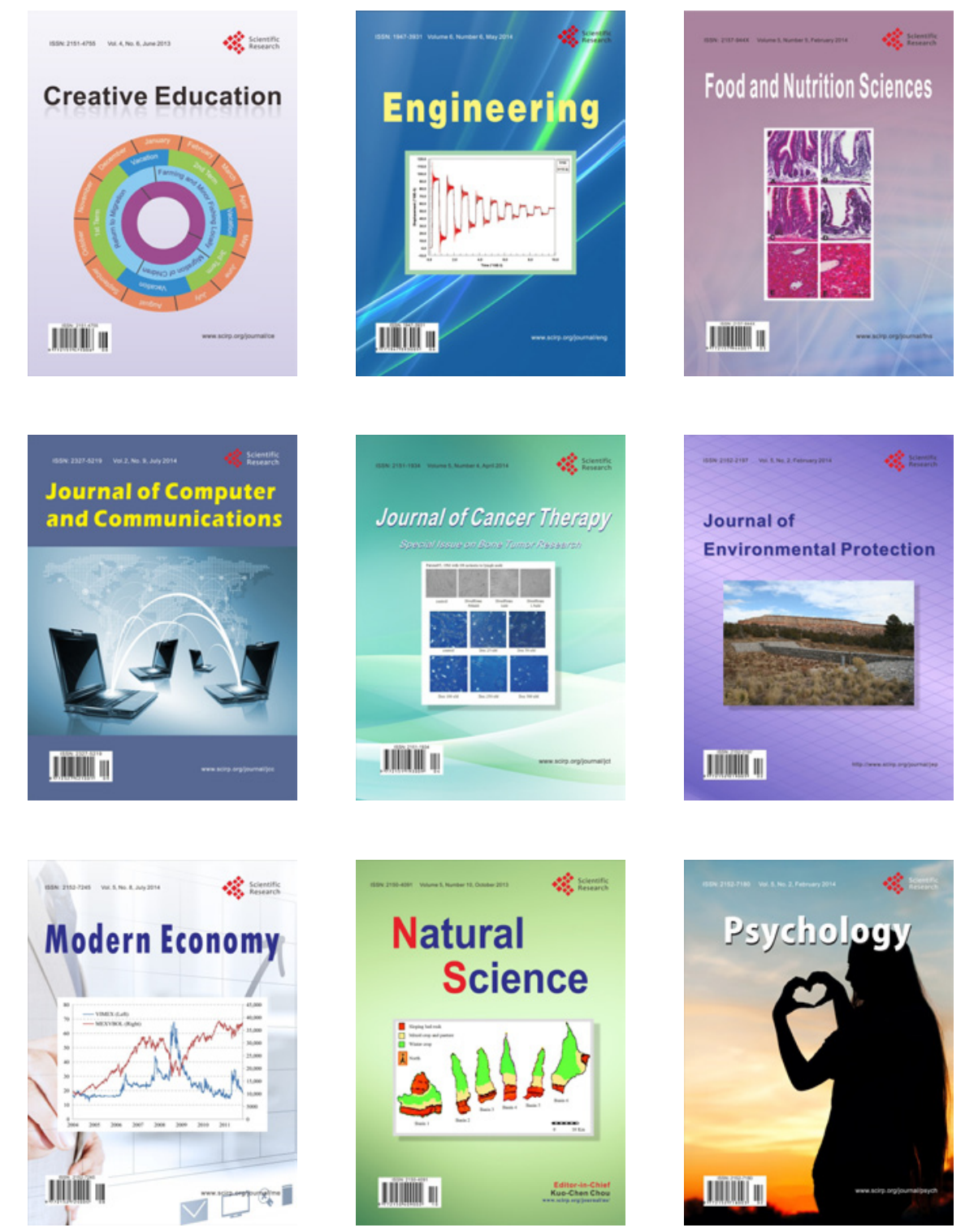